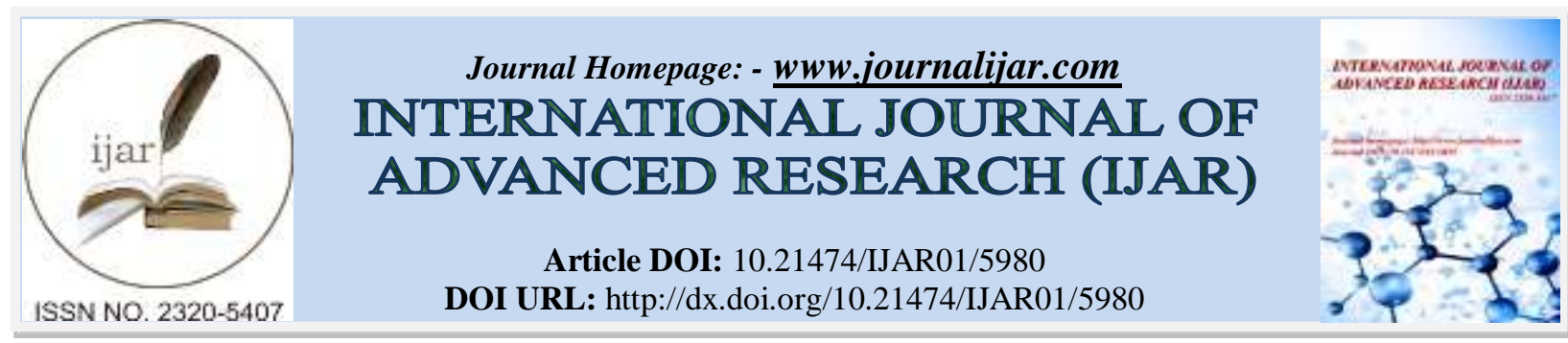

RESEARCH ARTICLE

\title{
EFFECT OF SELECTED YOGIC EXERCISES TOWARDS IMPROVEMENT OF SOME SPECIFIC NEUROPSYCHOLOGICAL PARAMETERS, SOME HEALTH RELATED FITNESS FACTORS IN SPECIALLY ABLED (DEAF AND DUMB) FEMALE SCHOOL CHILDREN.
}

Satabdi Mondal ${ }^{1}$ and Pathikrit Bandopadhyay ${ }^{1}$

Department of Physical Education. University of Kalyani, Kalyani, Nadia-741235.

\section{Manuscript Info}

Manuscript History

Received: 06 October 2017

Final Accepted: 08 November 2017

Published: December 2017

Key words:-

Deaf and dumb female school children,

Neuropsychological parameters, Yogic exercises.

\begin{abstract}
Background: Yoga is mind-body technique involving a set of physical exercises performed in synchronization with breathing, relaxation and meditation. 'Deaf and Dumb' is used to describe persons who are unable to hear the spoken words of others, and who, consequently, remain dumb. In this present study an attempt has been made to study the impact of selected yogic exercises on the visual perception, some health related fitness factors, alpha rhythm of cerebral cortex and attention bias in cerebellar hemisphere in the especially able female students.

Methods: In this study we have taken 60 female subjects and they were divided into two group namely control and experimental with equal size i.e.30 subjects in each group. Various analyses were done according to the standard protocols.

Results: The results of this present study showed that selected yogic exercises play an important role in development of some specific neuropsychological parameters in especially able female school children.

Conclusion: It can be concluded from the study that improvement of specific neurological, neuropsychological functions and specific fitness components and their integration, remedial training, may focus upon one area where yogic exercises play an important role in specially able female school students.

Copy Right, IJAR, 2017,. All rights reserved.
\end{abstract}

\section{Introduction:-}

Yoga is a mind-body technique involving a set of physical exercises performed in synchronization with breathing, relaxation and meditation. It is the best means for achieving physical, mental, social and spiritual well being of the practitioners.

Healthy life can be considered as resultant of yogic techniques (Yadav et al., 2015). Ithas been observed that yoga practitioners are physically and mentally healthier, having better coping skills to stressors than the normal population. It is to be emphasized that yoga is very effective for managing of all-pervading stress and stress-related disorders. Knowledge of inexpensive, effective and easily administrable yogic techniques by health professionals will go a long way in helping us to achieve the WHO goal of providing "physical, mental, spiritual and social health" to the society 
Today, holistic treatment modality has drawn the attention. Long period meditation produces definite changes in perception, attention, and cognition. ${ }^{1}$ Significant changes in the visual perception of advanced mediators, who were able to distinguish subtle differences in colour and shade, and were on the whole more perceptually sensitive, were reported. $^{2}$ Earlier study described an increase in visual sensitivity following the practice of the Buddhistic meditation. ${ }^{3}$ Scientific evidence shows that practice of yoga and meditation has tremendous impact on the functioning of nervous system. Yoga promotes relaxation in the practitioners but at the same time helps them in increasing their attention and other cognitive abilities.

'Deaf and Dumb' is used to describe persons who are unable to hear the spoken words of others, and who, consequently, remain dumb. Deafness and dumbness are the cause and consequence, respectively. Thus the term "deaf and dumb" is a misnomer. Deaf and dumb is a very common type of disability seen in our society not in a very negligible quantity. From their childhood, it is essential to take special care and attention to give them ample opportunity to be self sufficient in future. That is why various schools have been established for the special populations in our country starting from late seventies up to date.

Identification of the degree of preservation or impairment of an individual's capacities and to determine the real cognitive state of a particular function is the main objective of neuropsychological assessment. ${ }^{4,5}$ The two main goals of assessment of visual object and space perception forms part of any comprehensive neuropsychological assessment are the identification of stimuli and their localization. ${ }^{6}$

Earlier study showed that at the thalamic level, the sensory information processing is facilitated during the practice of pranayama, ${ }^{7}$ and meditation. ${ }^{8}$ These two practices, along with yoga following 10 days of practice were found to bring about an improvement in steadiness of hand in college students. ${ }^{8}$ It was believed that this improvement is due to improvement of eye-hand co-ordination, attention, concentration, and relaxation, as well.

Therefore in this present study an attempt has been made to study the impact of selected yogic exercises on the visual perception, some health related fitness factors, alpha rhythm of cerebral cortex and attention bias in cerebellar hemisphere in the specially abled female students.

\section{Materials and method:-}

\section{The subject :-}

The subjects for this study were selected randomly from Hellen Keller Bodhir Vidhalaya, Kolkata. A total 60 students were selected ages range between 16-17 yrs were selected as the subjects for the present study.

\section{Experimental design of the study:-}

60 female subjects were selected for this study of which they were divided into two group namely control and experimental with equal size i.e. 30 subjects in each group. After a pilot study of 5 weeks duration we had observed that whether these exercise at all causing any significant changes in the parameters that were inculded in the study, we have only included those components in the study which we have found significant after giving yogic exercises of 5 weeks. After the pilot study we had tested whether amongst the subjects who were selected for the study at all have any significant difference of these parameters i.e. flexibility, balance, visual perceptions, attention bias and alpha background rhythm due to yogic exercises of 5weeks. We had taken those 60 female subjects those were not shown any significant differences in changes of these parameters due to yogic exercises of 5 weeks and divide randomly into two groups i.e. control(no yogic exercises were given) and experimental(yogic exercises were given for 10weeks).

\section{Measurement of personal data:-}

i) Age: The age of the subjects were noted in the nearest year according to information of school registration. ${ }^{9}$

ii) Height: Height was measured through a stick marked accordingly to scale. The Height was taken in the centimeters. $^{10}$

iii) Weight: The subjects were instructed to stand on a standard weighing machine on both feet equal and bare footed. The measurement was taken in the nearest $\mathrm{kg} .{ }^{11}$ 


\section{Procedures for administering the tests:-}

The subjects were assembled and informed about the purpose of the study. They were instructed to complete the tests following standard procedure. They were asked to do their best. The following procedures were maintained for the proper administration of the tests.

\section{Selected yogic practice:-}

The subjects of the experimental group were underwent 10weeks of yogic exercises with a specialist in yogic exercises, the teacher of that school and researcher herself under strict observations. The subjects of the experimental group were underwent the following yogic exercises following the standardized protocol of Singh et al., 2006. ${ }^{12}$

For warm up: Pranayam (Anuloma and viloma, Sitali) exercises was first administered followed by Vazerasana (The Kneeling) and Uttanpadasana (double legs rising).

After that the following asans were administered to the subjects under strict supervision.

1. Sarvangasana (The shoulder stand)

2. Halasana (The Plough).

3. Matsyasana (The Fish).

4. Ustrasana (The Kneeling Wheel).

5. Suptvezrasana (The Kneeling Pose).

6. Ardhamatsyenderasana (The half Spinal Twist).

For Cooling down Savasana asan was administered.

Criterion measure:-

Specific Neurological, Neuropsychological and some selected Physical fitness parameters were measured for the present investigations.

1. Fitness Parameters:-

2. Balance

3. Flexibility

4. Neuropsychological:-

5. Greyscales task (Mattingley et al., 1994) for attention bias. ${ }^{13}$

6. Visual perception test (Warrington \& James, 1991) by Visual Perception Test Battery. ${ }^{14}$

7. Neurological Parameter:-

8. Alpha background rhythm of the cerebral cortex was measured by Electroenchephalography

\section{Balance: Stork stand test:-}

The stork balance test requires the person to stand on one leg. This test is usually usedto assess the ability of the subject to balance on the ball of the foot. The subjects were said to remove the shoes and place there hands on the hips, then position the non-supporting foot against the inside knee of the supporting leg. One minute was given to the subjects to practice the balance. The subject raised the heel to balance on the ball of the foot. As the heel was raised from the floor, the stopwatch was started. The stopwatch was stopped on the occurrance of the following cases :

1. The hand(s) come off the hips

2. The supporting foot swivels or moves (hops) in any direction

3. The non-supporting foot loses contact with the knee.

4. The heel of the supporting foot touches the floor.

Scoring: The total time in seconds is recorded. The score was calculated from the best of three attempts. The adjacent table lists general ratings for this test.

\section{Flexibility: Sit and Reach Test:-}

This test was carried out to assess the flexibility of the lower back and hamstring muscles. This test involved the sitting on the floor with legs out straight ahead. Feet (shoes off) were placed with the soles flat against the box, shoulder-width apart. If required, the tester held both knees flat against the floor. The hands were placed on top of each other and palms were faced down, the subject reached forward along the measuring line as far as possible. After three practice reaches, the fourth reach was held for at least two seconds while the distance was recorded. It was ensured that there were e no jerky movements and that the fingertips remain level and the legs flat. 
Scoring: The score is recorded to the half inch as the distance reached by the tip of the fingers. The usual scale was used for the Presidents Challenge testing, which has the zero mark at 9 inches $(23 \mathrm{~cm})$ before the feet; therefore, the score is 9 inches if the subject can reach their toes. All the scores were converted to centimeters.

\section{Gray scale task:-}

The gray scales task was first developed by Mattingley, Bradshaw, Nettleton, and Bradshaw (1994) ${ }^{13}$ as a means of assessing spatial biases in cerebral hemisphere. The task required participants to judge which of two left-right mirror-reversed brightness gradients (greyscales) appears darker overall. For each stimulus pair, one of the greyscales was shaded from black on the left to white on right, and the other was shaded in the reverse direction. Because the stimuli were aligned vertically, one above the other, participants' choices (top versus bottom) were orthogonal to the direction of the brightness gradients, thus reducing the potential influence of response biases.

Greyscales stimuli were created using a computer graphics package and printed in landscape orientation on white A4 paper sheets. Each and every stimulus card consisted of a pair of horizontal rectangles; one was placed immediately above the other. Each rectangle had a height of $20 \mathrm{~mm}$ and had a width that varied from 120 to $260 \mathrm{~mm}$ in $20 \mathrm{~mm}$ increments. Black fine outline of $0.5 \mathrm{~mm}$ was used to define each rectangle, and was shaded continuously from black at one end to white at the other. For each stimulus pair, one rectangle was darker at the left end and the other was darker at the right end [Figure 1]. Greyscale stimuli of each rectangle were presented four times in pseudorandom order, with the positions of the rectangles (top/bottom) counterbalanced, making a total of 32 items.

\section{Visual perception test:-}

The Visual Object and Space Perception Battery (VOSP) ${ }^{14}$ consists of 4 subtests that measure visual object perception (Incomplete Letters, Silhouettes, Object Decision, and Progressive Silhouettes) and 4 visual space perception tasks (Dot Counting, Position Discrimination, Number Location, and Cube Analysis). In a sample of healthy, normal older adults, this two-factor model of visuo-spatial perception as proposed by the authors of the test ${ }^{11}$ has recently been proven to be accurate using a confirmatory factor analysis approach.

The VOSP also contains a screening test that checks whether the subject's visual sensory capacities are sufficiently intact to permit further examination (Shape Detection Screening). It consists of 20 stimuli, 10 of which contain an incomplete form of the letter " $\mathrm{X}$," while the other 10 do not. The subject is required to determine whether an $\mathrm{X}$ is present. According to the test's manual, subjects with a score of 15 or lower should not be further tested. Within the Objects Perception part of the battery the incomplete Letters subtest consists of 20 letters that are $70 \%$ degraded; the subject has to identify the letters. The Silhouettes subtest consists of 15 silhouettes of animals and 15 of inanimate objects, drawn from an unusual perspective. Subjects are required to identify the drawings. For Object Decision, 4 figures are shown simultaneously to the subject only one of which corresponds to a real object; the other three are nonsense form distracters. The subject is required to identify the real object, shown at a rotation of $75 \%$. The Progressive Silhouettes subtest consists of 2 series of stimulus cards (depicting a gun and a trumpet), each consisting of 10 silhouette drawings, with each successive drawing revealing progressively more details of the object.

The subject is required to identify the object as early as possible (in this subtest, higher scores imply worse performance). Within the Spatial Perception part of the VOSP the first subtest is Dot Counting. This task consists of 10 cards with 5 to 9 dots on each. The subject has to identify the number of dots presented on each stimulus card. The Position Discrimination subtest consists of 20 cards. Each shows two squares containing dots. The subject has to decide which square has the dot in the centre. The Number Location subtest consists of 10 cards. Each shows 2 squares. The top square contains randomly placed numbers while the lower square shows a black dot, placed in the same position as one of the numbers above, and which the subject has to identify. The last subtest, Cube analysis, presents 10 stimuli where the subject is asked to determine the number of cubes shown on each stimulus card [Figure 2].

\section{Neurological Parameter:-}

The $\alpha$-background rhythms of the cerebral cortex of the subjects were measured by Electroenchephalography.

\section{Statistical procedure:-}

Students-t Test for paired group observation and one tail was administered for analysis of data to observe whether selected yogic practise can improve the neurological, neuro-psychological and fitness parameters before and after experimental time period for both the control and experimental group. 


\section{Results:-}

Presentation of the data:-

In the present study the personal data includes age, height and weight (data not shown).

Table 1 represents the Mean \pm SEM values of balance of the subjects of control group before and after experimental time period of yogic practise. From the table it has observed that the ' $t$ ' value is 0.39 which is not significant. This table also represents the Mean \pm SEM values of balance of the subjects of experimental group before and after experimental time period. From the table it has observed that the ' $\mathrm{t}$ ' value is 3.05 which is significant. Hence it can be inferred that selected yogic exercise improves the balance of the subjects.

Table 2 also represents the Mean \pm SEM values of flexibility of the subjects of control group before and after experimental time period. From the table it has observed that the ' $t$ ' value is 0.007 which is not significant. This table also represents the Mean \pm SEM values of flexibility of the subjects of experimental group before and after experimental time period of yogic practise. From the table it has observed that the ' $t$ ' value is 3.32 which is significant. Hence flexibility increased as the results of selected yogic practise.

Table 2 represents the data of grey scale task of the subjects of control and experimental groups before and after experimental time period of yogic practice. From the table it has observed that in case of experimental group ' $t$ ' value is significant at 0.01 level. Hence the yogic exercises do have effect on reduction of the attention bias that causes reduction in recurring thoughts. But in case of control group the difference between the values of pre and post experiments is not significant.

Table 2 represents the Mean \pm SEM values of visual perception of the subjects of control group before and after experimental time period. From the table it has observed that the ' $\mathrm{t}$ ' value is 1.12 which is not significant. This table also represents the Mean \pm SEM value of visual perception of the subjects of experimental group before and after experimental time period of yogic practise. From the table it has observed that the ' $t$ ' value is 3.32 which not significant. Hence as yogic exercise improves $\alpha$-wave of cortical rhythm therefore it has connection with visual cortex, so it can be inferred that yogic exercise do improves visual perception.

Table 2 also represents the values of $\alpha$-wave of cortical rhythm to determine cerebral cortex functioning of the subjects of control group before and after experimental time period. From the table it has observed that the ' $t$ ' value is 1.23 which is not significant. This table also represents the Mean $\pm \mathrm{SEM}$ value of $\alpha$-wave of cortical rhythm of the subjects of experimental group before and after experimental time period of yogic practise. From the table it has observed that the ' $t$ ' value is 3.351 which is significant. Therefore yogic practise do improve the alpha cortical rhythm which represents better cerebral cortex functioning.
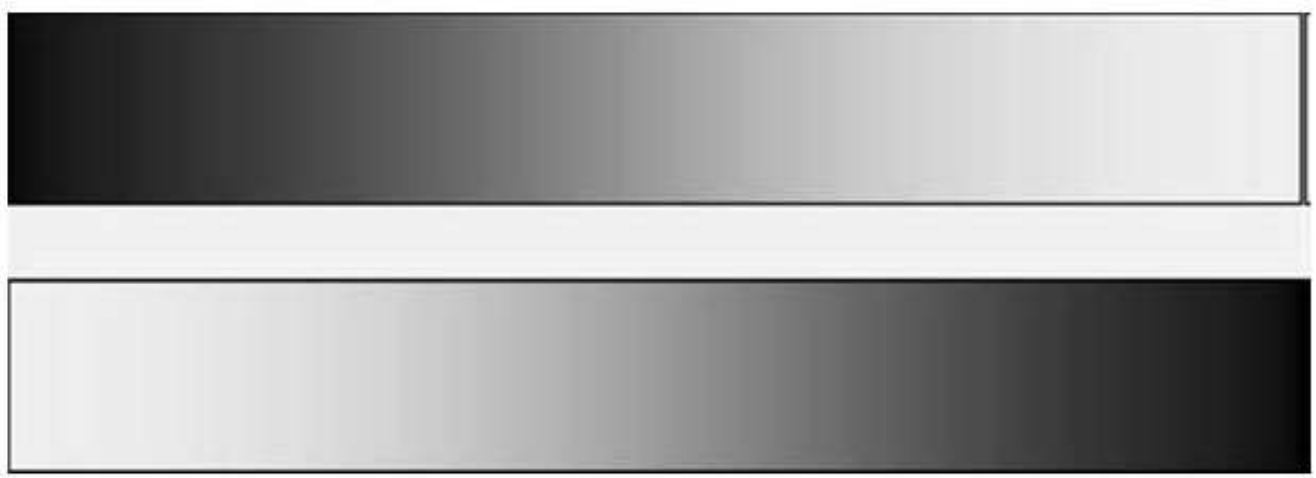

\section{Figure 1}

Figure 1:- Sample stimulus from the greyscales task as by Mattingley et al., 1994. The two rectangles are equal in overall brightness. 


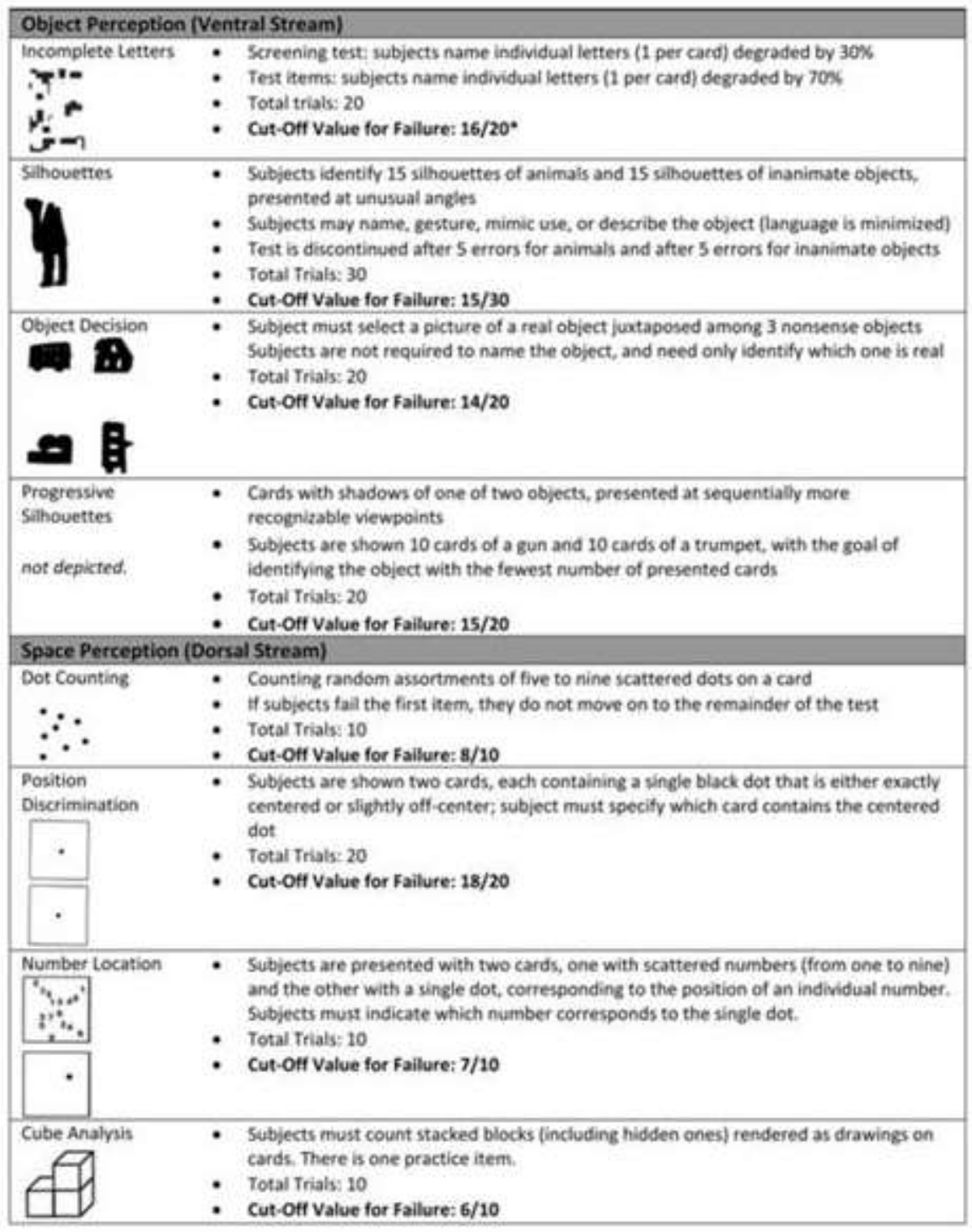

\section{Figure 2}

Figure

perception test items by Warrington \& James, 1991.

2:- Visual

Table 1:- Balance (measured in sec) and flexibility (measured in $\mathrm{cm}$ ) of the subjects of control and experimental groups before and after experimental time periods. Values are expressed as Mean \pm SEM for all groups.

\begin{tabular}{|l|l|l|l|l|l|}
\hline Parameters & Groups & $\begin{array}{l}\text { Types of } \\
\text { experiments }\end{array}$ & Mean \pm SEM & t value & $\begin{array}{l}\text { Level } \\
\text { significance }\end{array}$ \\
\hline $\begin{array}{l}\text { Balance(measured in } \\
\text { sec) }\end{array}$ & Control & $\begin{array}{l}\text { Before } \\
\text { Experiment } \\
\text { (N=30) } \\
\text { After } \\
\text { Experiment } \\
\text { (N=30) }\end{array}$ & $51.25 \pm 0.40$ & 0.39 & $\mathrm{P}>0.05$ \\
\hline
\end{tabular}




\begin{tabular}{|c|c|c|c|c|c|}
\hline & Experimental & $\begin{array}{l}\text { Before } \\
\text { Experiment } \\
(\mathrm{N}=30) \\
\text { After } \\
\text { Experiment } \\
(\mathrm{N}=30)\end{array}$ & $\begin{array}{l}51.23 \pm 0.07 \\
56.21 \pm 0.10^{*}\end{array}$ & 3.05 & $\mathrm{P}<0.01$ \\
\hline \multirow[t]{2}{*}{$\begin{array}{l}\text { Flexibility (measured } \\
\text { in } \mathrm{cm} \text { ) }\end{array}$} & Control & $\begin{array}{l}\text { Before } \\
\text { Experiment } \\
(\mathrm{N}=30) \\
\text { After } \\
\text { Experiment } \\
(\mathrm{N}=30)\end{array}$ & $\begin{array}{l}8.55 \pm 0.55 \\
2.59 \pm 0.53\end{array}$ & 0.0076 & $\mathrm{P}>0.05$ \\
\hline & Experimental & $\begin{array}{l}\text { Before } \\
\text { Experiment } \\
(\mathrm{N}=30) \\
\text { After } \\
\text { Experiment } \\
(\mathrm{N}=30)\end{array}$ & $\begin{array}{l}8.42 \pm 0.57 \\
13.82 \pm 0.67 *\end{array}$ & 3.32 & $\mathrm{P}<0.005,0.05$ \\
\hline
\end{tabular}

* refers to the significant value

Table 2:- Grey scale task, visual perception test results and alpha cortical rhythm (measured in $\mathrm{Hz}$ ) of the subjects of control and experimental groups before and after experimental time periods. Values are expressed as Mean \pm SEM for all groups.

\begin{tabular}{|c|c|c|c|c|c|}
\hline Parameters & Groups & $\begin{array}{ll}\text { Types } \\
\text { experiments }\end{array}$ of & Mean \pm SEM & $\mathrm{t}$ value & $\begin{array}{ll}\text { Level } & \text { of } \\
\text { significance }\end{array}$ \\
\hline \multirow{2}{*}{$\begin{array}{l}\text { Grey scale } \\
\text { task }\end{array}$} & Control & $\begin{array}{l}\text { Before Experiment } \\
(\mathrm{N}=30) \\
\text { After Experiment } \\
(\mathrm{N}=30)\end{array}$ & $\begin{array}{l}3.03 \pm 0.02 \\
2.41 \pm 0.01 \\
\end{array}$ & 2.83 & $\mathrm{P}<0.01$ \\
\hline & Experimental & $\begin{array}{l}\text { Before Experiment } \\
(\mathrm{N}=30) \\
\text { After Experiment } \\
(\mathrm{N}=30)\end{array}$ & $\begin{array}{l}0.53 \pm 0.07 \\
0.65 \pm 0.06^{*} \\
\end{array}$ & 0.27 & $P>0.05$ \\
\hline \multirow{2}{*}{$\begin{array}{l}\text { Visual } \\
\text { perception } \\
\text { test }\end{array}$} & Control & $\begin{array}{l}\text { Before Experiment } \\
(\mathrm{N}=30) \\
\text { After Experiment } \\
(\mathrm{N}=30)\end{array}$ & $\begin{array}{l}11.22 \pm 0.26 \\
13.23 \pm 0.12 \\
\end{array}$ & 1.12 & $\mathrm{P}>0.05$ \\
\hline & Experimental & $\begin{array}{l}\text { Before Experiment } \\
(\mathrm{N}=30) \\
\text { After Experiment } \\
(\mathrm{N}=30)\end{array}$ & $\begin{array}{l}13.22 \pm 0.37 \\
18.62 \pm 0.27 * \\
\end{array}$ & 3.32 & $\mathrm{P}<0.005$ \\
\hline \multirow{2}{*}{$\begin{array}{l}\text { Alpha } \\
\text { cortical } \\
\text { rhythm } \\
\text { (measured in } \\
\mathrm{Hz} \text { ) }\end{array}$} & Control & $\begin{array}{l}\text { Before Experiment } \\
(\mathrm{N}=30) \\
\text { After Experiment } \\
(\mathrm{N}=30)\end{array}$ & $\begin{array}{l}9.5 \pm 0.04 \\
9.4 \pm 0.10 \\
\end{array}$ & 1.23 & $\mathrm{P}>0.05$ \\
\hline & Experimental & $\begin{array}{l}\text { Before Experiment } \\
(\mathrm{N}=30) \\
\text { After Experiment } \\
(\mathrm{N}=30)\end{array}$ & $\begin{array}{l}8.67 \pm 0.07 \\
10.60 \pm 0.10^{*}\end{array}$ & 3.351 & $\mathrm{P}<0.01$ \\
\hline
\end{tabular}

* refers to the significant value.

\section{Discussion:-}

Alpha rhythm is a rhythm of $8-13 \mathrm{~Hz}$ which occurs during wakefulness over the posterior part of the head. This rhythm occurs generally over the occipital areas with higher voltage. Amplitude is variable but is mostly below 50 $\mu \mathrm{V}$ in adults. It is attenuated by various visual and mental effort. ${ }^{15}$ The occipital region is the maximal alpha rhythm 
voltage in $65 \%$ of adults and $95 \%$ of children. ${ }^{16,17}$ Changes in the visual information causes the changes in the alpha rhythm, either locally or globally, as vigilance changes. While the origin of the alpha rhythm can be localized within the primary and secondary visual areas of the occipital and partly parieto-occipital cortex using multi-channel electroencephalographic (EEG) or magneto encephalographic (MEG) derivations, ${ }^{18}$ the brain regions participating in the state fluctuations which are expressed in the variable form of the alpha rhythm as well as their functional role within these changes are not yet conclusively described. Moreover, earlier research study by Aich et al., 2014 shows the Presence of seizure activity and absence of alpha rhythm in EEG is significantly correlated to each other. ${ }^{19}$ In this study we have observed significant improvement in frequency of alpha rhythm due to 10 weeks of continuous yogic exercise suggesting the fact that yogic exercise not only improve their visual information processing but also reduce the risk of several seizure related disorders.

Attention bias is the tendency of our perception to be affected by our recurring thoughts. In the present study, researcher has replicated earlier findings of a subtle but consistent leftward bias in especially able participants on the greyscales task. ${ }^{13}$ In this study it was observed that yogic exercise have reduced the attention bias of the right hemisphere. As study reported in case of deaf and dumb people attention biases are much more inclined towards there retarding deformities and research studies has also conferred several types of cognitive bias occur due to an attention bias. Therefore 10 weeks yogic exercise practise reduces the same and thus therefore proves beneficial for them.

The Visual Object and Space Perception Battery (VOSP) is based upon Warrington's model, ${ }^{14}$ which distinguishes 3 subtypes of impaired object recognition: 1) disorders of visual sensory discrimination;2) appreciative agnosia and 3) associative agnosia, which refers to disorders when deriving the meaning of visually presented objects, even in the presence of normal sensory and perceptual abilities. The VOSP can be used for characterizing the cognitive state of visual perception in both, normal and pathological populations. The recent application of the VOSP has been reported in patients with multiple sclerosis by studying how cognitive and neurological patient's admission status related to their benefit from neuro-rehabilitation, although visual perception resulted in no significant influence. ${ }^{20}$ The impairment in pre-attentive visual processing in patients with Parkinson disease has been recently demonstrated. $^{21}$ It therefore seems appropriate to extend such studies to other populations. In this study improvement of visual perception after yogic exercise suggests the fact that as alpha rhythm in visual cortical areas improves after yogic exercise which aids for improvements in visual perception, particularly in the context of these especially abled people, because human eye brain system handles several complex tasks, therefore yogic exercise aids in this development.

Study by Ghosh, 2014 has indicated that in speed, agility and muscular endurance there were no significant difference found between the normal and deaf \& dumb school boys of West Bengal. ${ }^{22}$ However, significant difference was found in flexibility between the normal and deaf and dumb school boys of West Bengal where the normal boys were better than the deaf \& dumb boys. ${ }^{23}$ In this study balance and flexibility are the two important component of the fitness were taken because cortical areas are also concerned with balance maintenance of body system along with cerebellum. Research study by Telles et al., 2013 proves significant effect of yogic exercises on physical and fitness parameters in school students of Hariyana. ${ }^{24}$ Therefore in this study it has been observed a significant change in fitness and balance after yogic exercise co relates with the earlier findings.

\section{Conclusions:-}

In conclusion it can be stated further that improvement of specific neurological and neuropsychological functions and their integration, can be focus upon yogic exercises which can also be used to develop the sensory-motor functions, improvement of higher thought processes, integrative abilities, and social and emotional growth in these populations of specially abled persons. Principles of teaching is to direct the attention as well as to improve the individualization, and personalization to enhance the ability of teaching as well as attention and therefore although the study has some limitations but it can be stated that yogic exercise may have other several roles on other neuropsychological and neurological parameters which will be unveiled through research study directed on this field.

\section{Acknowledgement:-}


This work is supported by funds available under Personal Research Grant available to Pathikrit Bandopadhyay from Kalyani University.

\section{Conflicts of interest:-}

There are no conflicts of interest.

\section{References:-}

1. Kramer RS, Weger UW, Sharma D. The effect of mindfulness meditation on time perception. Conscious and Cognition 2013;22:846-52.

2. Brown DP, Engler J. The stages of mindfulness meditation: A validation study. Journal of Transpersonal Psychology 1980;12:143-92.

3. Brown DP, Forte M, Dysart M. Visual sensitivity differences among mindfulness meditators and nonmeditators. Perceptual and Motor Skills 1984;58:727-33.

4. Ellis AW, Young AW. Human Cognitive Neuropsychology. Hove, UK: Erlbaum; 1988.

5. Peña-Casanova J, Guardia J, Bertran-Serra I, Manero RM, Jarne A. Shortened version of the Barcelona test (I): subtests and normal profiles. Neurologia 1997;12:99-111.

6. Farah M. Visual perception and visual imagery. In T. Feinberg, \& M. Farah (Eds.), Behavioral neurology and neuropsychology. Psychology Press New York: McGraw Hill;2003.

7. Telles S, Joseph C, Venkatesh S, Desiraju T. Alterations of auditory middle latency evoked potentials during yogic consciously regulated breathing in an attentive state of mind. International Journal of Psychophysiology 1992;14:189-98.

8. Telles S, Desiraju T. Recording of audioty middle latency evoked potentials during the practice of meditation on the syllable 'OM'. Indian Journal of Medicinal Research 1993;98:237-9.

9. Mondal SF, Bandopadhyay P. Effect of vitamin E supplementation and combined treadmill exercise towards the development of leg strength, explosive strength and exercise oxygen uptake of male students. Journal of Pharmacy Research 2014;8:958-62.

10. Mondal S, Bandopadhyay P, "Impact of KHO-KHO playing on physiological changes and development of some specific skill related physical fitness factors", Indian Journal of Applied Research, 2014, 4, 534-536.

11. Hoque A, Bandopadhyay P. Effect of vitamin e supplementation towards development of the anaerobic power and phosphate mediated recovery of sprinters. International Journal of Applied Pharmaceutics 2016;8:20-3.

12. Singh NN, Lancioni GE, Winton AS. Mindful parenting decreases aggression, noncompliance, and self injury in children with autism. Journal of Emotional and Behavioral Disorders 2006;14:169-77.

13. Mattingley JB, Bradshaw JL, Nettleton NC, Bradshaw JA. Can task specific perceptual bias be distinguished from unilateral neglect? Neuropsychologia 1994;32:805-17.

14. Warrington EK, James M. The Visual Object and Space Perception Battery (VOSP). Bury St. Edmunds, England: Thames Valley Test Co.: 1991.

15. Ware C, Purchase HC, Colpoys L, McGill M. Cognitive measures of graph aesthetics. Information Visualization 2003;1:103-10.

16. Kellaway P. Orderly approach to visual analysis: Elements of normal EEG and their characteristics in children and adults. In: Ebersole JS, Padley TA, editors. Current Practice of Clinical Electroencephalography.New York: Lippincott Williams and Wilkins: 2003.

17. Niedermeyer E. The normal EEG of the waking adult. In: Niedermeyer E, DaSilva L, editors. Electroencephalography: Basic Principles, Clinical Applications and Related Fields. New York: Lippincott Williams and Wilkins:1999.

18. Feige B, Scheffler K, Esposito F, Di Salle F, Hennig J, Seifritz E. Cortical and Subcortical Correlates of Electroencephalographic Alpha Rhythm Modulation. Journal of Neurophysiology 2005;93:2864 -72.

19. Aich TK. Absent posterior alpha rhythm: An indirect indicator of seizure disorder? Indian Journal of Psychiatry 2014;56:61-6.

20. Flachenecker P. Clinical Implications of Neuroplasticity - The Role of Rehabilitation in Multiple Sclerosis. Frontiers of Neurology 2015; 6:36-9.

21. Lieb R, Wittchen H, Höfler M. Parental psychopathology, parenting styles, and the risk of social phobia in offspring. Archives of General Psychiatry 2000;57:859-66.

22. GhoshSS. A comparative study on selected physical fitness components between deaf \& dumb and normal school boys of West Bengal. International Journal of Physical Education, Fitness and Sports 2014;3:52-9. 
23. Ghosh SS, Banerjee S. A comparative study on selected physical fitness components and personality traits between deaf and dumb and normal school girls of West Bengal. International Journal of Physical Education, Sports and Health 2015;1:59-63.

24. Telles S, Singh N, Bhardwaj AK, Kumar A, Balkrishna A. Effect of yoga or physical exercise on physical, cognitive and emotional measures in children: a randomized controlled trial. Child and Adolescent Psychiatry and Mental Health 2013;7:37-52. 